\title{
European survey shows poor association between soil organic matter and crop yields
}

\author{
Wytse J. Vonk (iD · Martin K. van Ittersum • Pytrik Reidsma • Laura Zavattaro • \\ Luca Bechini • Gema Guzmán • Annette Pronk • Heide Spiegel • \\ Horst H. Steinmann • Greet Ruysschaert • Renske Hijbeek
}

Received: 26 March 2020/ Accepted: 20 October 2020/Published online: 4 November 2020

(C) The Author(s) 2020

\begin{abstract}
A number of policies proposed to increase soil organic matter (SOM) content in agricultural land as a carbon sink and to enhance soil fertility. Relations between SOM content and crop yields however remain uncertain. In a recent farm survey across six European countries, farmers reported both their crop yields and their SOM content. For four widely grown crops (wheat, grain maize, sugar beet and potato), correlations were explored between reported crop yields and SOM content $(\mathrm{N}=1264)$. To explain observed
\end{abstract}

Electronic supplementary material The online version of this article (https://doi.org/10.1007/s10705-020-10098-2) contains supplementary material, which is available to authorized users.

W. J. Vonk $(\bowtie) \cdot$ M. K. van Ittersum .

P. Reidsma · R. Hijbeek

Plant Production Systems, Wageningen University and Research, Wageningen, The Netherlands

e-mail: wytsevonk@gmail.com

\section{Zavattaro}

Department of Agricultural Forest and Food Sciences, Università Degli Studi Di Torino, Turin, Italy

\section{Bechini}

Department of Agricultural and Environmental Sciences, Università Degli Studi Di Milano, Milan, Italy

G. Guzmán

Institute for Sustainable Agriculture-CSIC, Cordoba, Spain variability, climate, soil texture, slope, tillage intensity, fertilisation and irrigation were added as covariables in a linear regression model. No consistent correlations were observed for any of the crop types. For wheat, a significant positive correlation $(p<0.05)$ was observed between SOM and crop yields in the Continental climate, with yields being on average $263 \pm 4(95 \% \mathrm{CI}) \mathrm{kg} \mathrm{ha}^{-1}$ higher on soils with one percentage point more SOM. In the Atlantic climate, a significant negative correlation was observed for wheat, with yields being on average $75 \pm 2$ (95\% CI) $\mathrm{kg} \mathrm{ha}^{-1}$ lower on soils with one percentage point more SOM $(p<0.05)$. For sugar beet, a significant positive correlation $(p<0.05)$ between

\footnotetext{
A. Pronk

Agrosystems Research, Wageningen University and

Research, Wageningen, The Netherlands

H. Spiegel

Institute for Sustainable Plant Production, Austrian

Agency for Health and Food Safety, Vienna, Austria

H. H. Steinmann

Centre for Biodiversity and Sustainable Land Use, Georg-

August-Universität Göttingen, Göttingen, Germany

G. Ruysschaert

Flanders Research Institute for Agriculture, Fisheries and

Food Research (ILVO), Merelbeke, Belgium
} 
SOM and crop yields was suggested for all climate zones, but this depended on a number of relatively low yield observations. For potatoes and maize, no significant correlations were observed between SOM content and crop yields. These findings indicate the need for a diversified strategy across soil types, crops and climates when seeking farmers' support to increase SOM.

Keywords Soil organic matter - Crop yield . Europe $\cdot$ Arable farming $\cdot$ Survey

\section{Introduction}

Agricultural science has a long history of searching for correlations between soil organic matter (SOM) content and soil fertility (Russell 1977). SOM is found to affect soil water retention (Nyamangara et al. 2001; Zebarth et al. 1999), nutrient availability and the suppression of pests and soil borne diseases (Asirifi et al. 1994; Darby et al. 2006). While all these processes are beneficial for crop yields, the size of these benefits remains uncertain.

More recently, a number of studies attempted to quantify the direct benefits of SOM on crop yields. Several studies found a significant positive correlation (de Moraes Sa et al. 2014; Lucas and Weil 2012; Oldfield et al. 2019, 2020). However, others indicate that no significant effect of SOM on crop productivity could be found (Hijbeek et al. 2017a; Loveland and Webb 2003; Schjønning et al. 2018). These diverging findings call for a deeper search to understand the conditions under which SOM may contribute to improved soil fertility and crop yields.

Most of the mentioned studies used field or pot experiments. Findings in controlled experiments may however deviate from farmers' experience in the field with more varying circumstances and less controlled management. The inclusion of farmers' experiences would add a valuable dimension to the available data on SOM and crop yields. Even more so, because the benefits of SOM depend on farm management, as more intensive management and reliance on technical means reduce dependence of crop yield on SOM functions (van Noordwijk et al. 1997).

Next to management, the beneficial effect of SOM on crop yields depends on climates and soil types.
Increase in SOM content may also have potentially negative effects: slow nutrient mineralisation by organic matter, for example, might not supply nutrients at the precise moments when the crop needs those nutrients leading to potentially larger nutrient losses (Chen 2006).

In a recent large-scale farm survey across Europe, farmers were asked to report their average SOM content and crop yields. Analysis of these data could give further insight in the relationship between SOM and crop yields under actual farming conditions, taking into account the variation in climates, soil types and cultivated crops. Using these data, we aim to answer the following three research questions:

1. Can correlations be found between SOM content and crop yields under current European farming practices, based on farmers' observations?

2. What is the influence of climate, slope, soil texture and crop type on the correlation between SOM and crop yields?

3. How is the correlation between SOM and crop yields affected by farm management such as irrigation, tillage intensity and fertiliser use?

\section{Material and methods}

Study area

The relationship between SOM content and crop yields was analysed based on a farm survey conducted in 2013 as part of the European Catch-C project. Farm survey data for the following six countries was used: Austria, Belgium, Germany, Spain, Italy and the Netherlands. For each country, details on climates and respondents are listed in Table 1. Methodology related to the findings presented here is described below; more details about the Catch-C farm survey are described by Bijttebier et al. (2015).

Analysis of survey data

\section{Main variables}

The two main variables used for our analysis were observed yield (tonnes $\mathrm{ha}^{-1}$ ) from the crops of interest and the reported average SOM content (\%) across the whole farm. Representative crop yields for the last 
Table 1 Climate zones, number of survey respondents, average SOM content and reported crop yields per country

\begin{tabular}{|c|c|c|c|c|c|c|c|}
\hline Country & Climate zone & $\begin{array}{l}\text { \# Farmers } \\
\text { (response } \\
\text { rate) }\end{array}$ & $\begin{array}{l}\text { Average } \\
\text { SOM } \\
\text { content }(\%)\end{array}$ & $\begin{array}{l}\text { Average wheat } \\
\text { yield (tonnes } \\
\text { FM ha }^{-1} \mathrm{yr}^{-1} \text { ) }\end{array}$ & $\begin{array}{l}\text { Average maize } \\
\text { yield (tonnes } \\
\text { FM ha }{ }^{-1} \mathrm{yr}^{-1} \text { ) }\end{array}$ & $\begin{array}{l}\text { Average sugar } \\
\text { beet yield } \\
\text { (tonnes FM } \\
\text { ha }^{-1} \mathrm{yr}^{-1} \text { ) }\end{array}$ & $\begin{array}{l}\text { Average Potato } \\
\text { yield (tonnes } \\
\text { FM ha }^{-1} \mathrm{yr}^{-1} \text { ) }\end{array}$ \\
\hline Austria & Continental & $48(*)$ & $\begin{array}{l}3.01 \\
(\mathrm{~N}=30)\end{array}$ & $6.29(\mathrm{~N}=25)$ & $10.38(\mathrm{~N}=16)$ & $72.75(\mathrm{~N}=15)$ & $45.71(\mathrm{~N}=7)$ \\
\hline Belgium & Atlantic & $\begin{array}{l}983 \\
\quad(26 \%)\end{array}$ & $\begin{array}{l}2.73 \\
\quad(\mathrm{~N}=322)\end{array}$ & $9.00(\mathrm{~N}=111)$ & $\begin{array}{l}11.44 \\
\quad(N=159)\end{array}$ & $71.25(\mathrm{~N}=64)$ & $\begin{array}{l}44.01 \\
\qquad(\mathrm{~N}=170)\end{array}$ \\
\hline Germany & $\begin{array}{l}\text { Atlantic } \\
\text { Continental }\end{array}$ & $439(16 \%)$ & $\begin{array}{l}3.35 \\
(N=260)\end{array}$ & $7.26(\mathrm{~N}=190)$ & $9.83(\mathrm{~N}=31)$ & $66.75(\mathrm{~N}=83)$ & $40.87(\mathrm{~N}=49)$ \\
\hline Spain & Mediterranean & $208(*)$ & $\begin{array}{l}1.70 \\
(\mathrm{~N}=34)\end{array}$ & $3.00(\mathrm{~N}=3)$ & $13.00(\mathrm{~N}=2)$ & - & - \\
\hline Italy & Mediterranean & $310(*)$ & $\begin{array}{l}2.68 \\
\quad(N=100)\end{array}$ & $5.53(\mathrm{~N}=40)$ & $11.08(\mathrm{~N}=47)$ & $55.75(\mathrm{~N}=4)$ & - \\
\hline Netherlands & Atlantic & $\begin{array}{l}621 \\
\quad(10 \%)\end{array}$ & $\begin{array}{l}3.77 \\
\quad(\mathrm{~N}=516)\end{array}$ & $9.20(\mathrm{~N}=340)$ & $12.30(\mathrm{~N}=33)$ & $80.39(\mathrm{~N}=367)$ & $\begin{array}{l}51.70 \\
\quad(\mathrm{~N}=246)\end{array}$ \\
\hline Total & & 2609 & $\begin{array}{l}3.26 \\
\quad(\mathrm{~N}=1262)\end{array}$ & $8.31(\mathrm{~N}=709)$ & $\begin{array}{l}11.26 \\
(\mathrm{~N}=288)\end{array}$ & $76.77(\mathrm{~N}=533)$ & $\begin{array}{l}47.71 \\
\quad(\mathrm{~N}=470)\end{array}$ \\
\hline
\end{tabular}

$\mathrm{N}$ indicates the sample size

*Response rate is not known in these areas

years were asked. To obtain a substantial sample size, the analysis was done for four widely cultivated crops: grain maize, wheat, sugar beet and potato. Reported SOM content was often based on soil tests. If farmers were uncertain about their SOM level, they were given the option to leave the question open. The latter was much more apparent in countries where less knowledge was available to farmers about their soil status (e.g. Spain).

\section{Biophysical co-variables}

To explain correlations between SOM and crop yields, soil texture, slope and climate were included as biophysical co-variables. For soil texture, farmers indicated the farm area consisting of sand, loam or clay soils (1, 2 and 3 respectively). Following, in our analysis we calculated an average value for soil texture per farm. So for example, a farm with $50.0 \%$ sandy soils and $50.0 \%$ loamy soils would get an average texture value of 1.5. For slope, a similar procedure was followed with 1 indicating level land ( $0 \%)$ to 5 a steep slope $(>15 \%)$.

Climate type was based on the climate zones described by Metzger et al. (2005). To create a larger sample size per climate zone, they were aggregated into an Atlantic (Atlantic north; Atlantic central), Continental (Continental; Pannonian) and Mediterranean (Mediterranean north; Mediterranean south) zone.

\section{Farm management co-variables}

Irrigation, tillage practice and fertiliser use were included as management co-variables. A weighted tillage intensity value was calculated similar to the other weighted values resulting in a value between 1 and 3; 1 meaning solely no tillage and 3 meaning solely ploughing. Irrigation was indicated by yes or no: a farm with or without irrigation use.

Fertiliser use was reported in amounts of slurry, farm yard manure, compost and mineral fertiliser. All fertiliser types were converted into $\mathrm{kg} \mathrm{N} \mathrm{ha}^{-1} \mathrm{yr}^{-1}$, using $\mathrm{N}$ coefficients (nitrogen fertiliser replacement value) based on literature (Supplementary Table 1). Mineral fertiliser was reported in $\mathrm{kg} \mathrm{N} \mathrm{ha}^{-1} \mathrm{yr}^{-1}$.

Data organization and outlier removal

To increase the accuracy of reported SOM contents, farmers could indicate if they were uncertain about the average SOM content of their farm. Farmers who did 
not indicate their average SOM content, or were uncertain about it, were excluded from analysis. In addition, SOM values above $12.0 \%$ were removed (as this might refer to a peat soil; $\mathrm{N}=96$ ). Soil organic carbon, which is used in Germany and Belgium, was converted into SOM using the conventional factor of 1.724 (Pribyl 2010). Soils containing less than $0.1 \%$ SOM were considered outliers and also removed from analysis $(\mathrm{N}=9)$. Because we were interested in the shape of the point cloud, we only removed extreme crop yield outliers per country [Q3 $+3 *$ inter quartile range (IQR)], which were considered biophysically impossible $(\mathrm{N}=28)$. Outliers of total effective fertiliser application were removed using 3.0*IQR (759 kg N ha $\mathrm{kr}^{-1} ; \mathrm{N}=47$ ).

Statistical analyses

\section{Multiple linear regression and model selection}

First, QQ-plots were made to assess if the data was normally distributed (Supplementary Figure S1). To assess the influence of SOM and different co-variables on crop yields, multivariate analyses were performed for each crop using the car package for R (Fox 2018), according to the following equation:

$$
\begin{aligned}
& \text { Yield } \sim \text { SOM }+ \text { climate }+ \text { texture }+ \text { slope } \\
& \quad+\text { tillageintensity }+ \text { effectivefertiliser }+ \text { irrigation } \\
& \quad+\varepsilon
\end{aligned}
$$

Initially a full model (Eq. 1, including all covariables) was run. Following, the explanatory power of the full model was compared with a reduced model (excluding SOM as an explanatory variable) to assess the added value of SOM to explain observed crop yields. Using this approach however bears a risk of overfitting the data. To account for overfitting, corrected Akaike information criterion (AICc) can be used to evaluate the explanatory power of statistical models and the relevance of co-variables.

Subsequently, a model selection was performed using AICc for each crop to assess variable importance, and specifically the importance of SOM in explaining crop yields. To this end, the dredge function from the MuMIn package for R-studio (Barton 2019) was used. Based on the AICc values (Giraud 2014) a model ranking was made. For all crop types, multiple top ranking models could be considered as the 'best' model, as their explanatory value was similar $(\triangle \mathrm{AICc}<2)$. The mean effect size of SOM on crop yield and corresponding $95 \%$ confidence intervals were calculated across these top ranking models. The first best model for every crop was further checked for significance using an Anova type 3 table [for models with interactions, from the car package (Fox 2018)].

\section{Quantile regression}

Linear regression does not investigate the shape of the point cloud from the data. To investigate if SOM influences minimum or attainable crop yields (the shape of the point cloud), a quantile regression was performed using the Quantreg package from Koenker et al. (2019). Quantile regression is similar to linear regression, but only investigates a certain part of the data. Lower and upper quantiles of the data were investigated: tau $=0.1$ and 0.9 . In this study, the 0.1 quantile gives an indication for minimum yield of a crop for a certain SOM content. The 0.9 quantile gives an indication for the attainable yield at a certain SOM content. Whether slopes of the lower and upper quantiles were significantly different from zero was assessed using the 'NID' method to calculate standard errors (Koenker et al. 2019).

\section{Results}

Reported SOM contents and crop yields

Shares of respondents that reported SOM content differed per country: in the Netherlands, the response proportion was the largest (83.1\%) and in Spain it was lowest $(16.3 \%)$. The average SOM content varied from $1.7 \%$ in Spain to $3.8 \%$ in the Netherlands. For all countries combined, the average SOM content was $3.26 \%$ (Table 1), with a median of $2.59 \%$ SOM.

The highest average crop yields were observed in the more northern European countries, the lowest in Spain and Italy. This was not the case for maize, with maize yields in Italy and Spain being similar to the more northern European countries. Among the respondents in Spain, none of the farmers cultivated potato or sugar beet (Table 1). The average reported crop yields in this survey differed less than $15.0 \%$, both positive 
and negative, from national statistics averages (EUFADN 2019) for all countries, except for wheat yield in Austria (22.7\% higher reported average yield).

SOM and crop yields

Wheat yields were significantly correlated with SOM content using simple linear regression $(p<0.05)$, but the size and the direction differed per climate zone: the correlation being negative in the Atlantic climate, and positive in the Continental climate (Fig. 1). For the other crops, no correlation was observed using simple linear regression.

To assess the influence of SOM on crop yields when including effects of all co-variables (such as soil texture), a multivariate regression was done. Descriptive information about the co-variables can be found in supplementary Table S2. When comparing a full model (Eq. 1, with SOM as an explanatory variable) with a reduced model (without SOM as an explanatory variable), no differences were found in the total explanatory value. $\mathrm{R}^{2}$ adjusted was the largest for wheat with (0.5497) and without SOM (0.5503). In all cases, $\mathrm{R}^{2}$ adjusted were similar between the full model and the reduced model, with the largest difference for maize (0.0236).

Based on AICc values, a model ranking was made (Supplementary Table 3). The number of top ranking models having a similar AICc value differed per crop type (wheat $\mathrm{N}=8$; maize $\mathrm{N}=3$; sugar beet $\mathrm{N}=5$ and potato $\mathrm{N}=21$ ). For wheat, maize and sugar beet, SOM was included as an explanatory variable for crop yields in all the top ranking models. For potato, SOM was included as an explanatory variable in more than

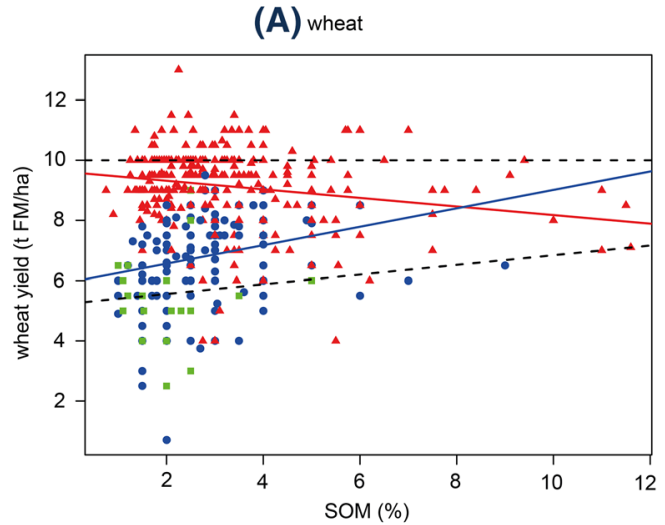

(B) grain maize

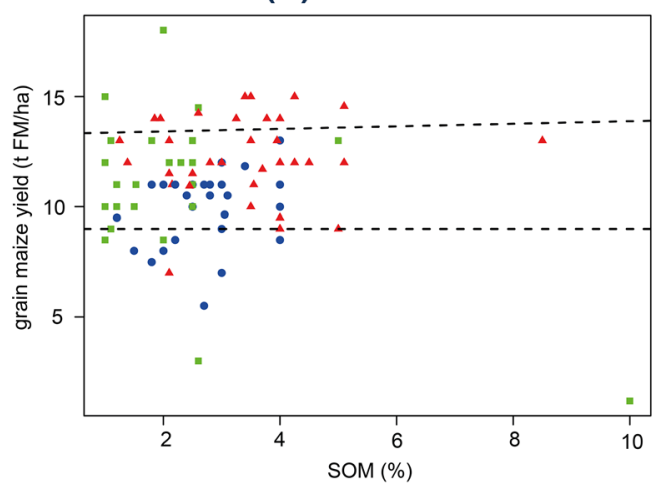

Fig. 1 Influence of climate on the relation between SOM and wheat yield (a), maize yield (b), sugar beet yield (c) and potato yield (d). The data points for yield are given different colours and shapes per climate: Green square = Mediterranean, Blue
(C) sugar beet

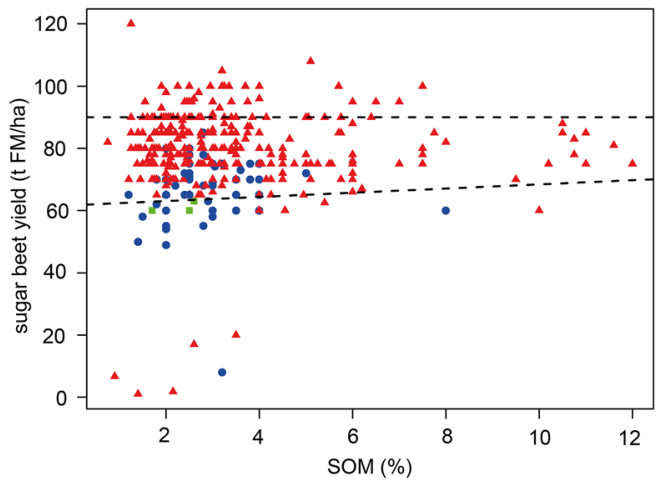

(D) potato

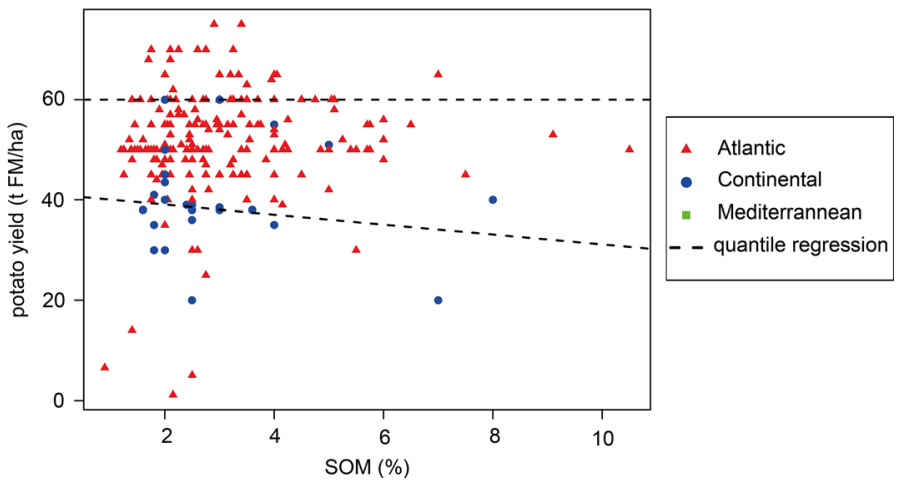

circle $=$ Continental and Red triangle $=$ Atlantic. The coloured lines indicate significant simple linear regression for each climate zone. The black dotted lines indicate two quantiles of the data $(\operatorname{tau}=0.1$ and 0.9$)$ 


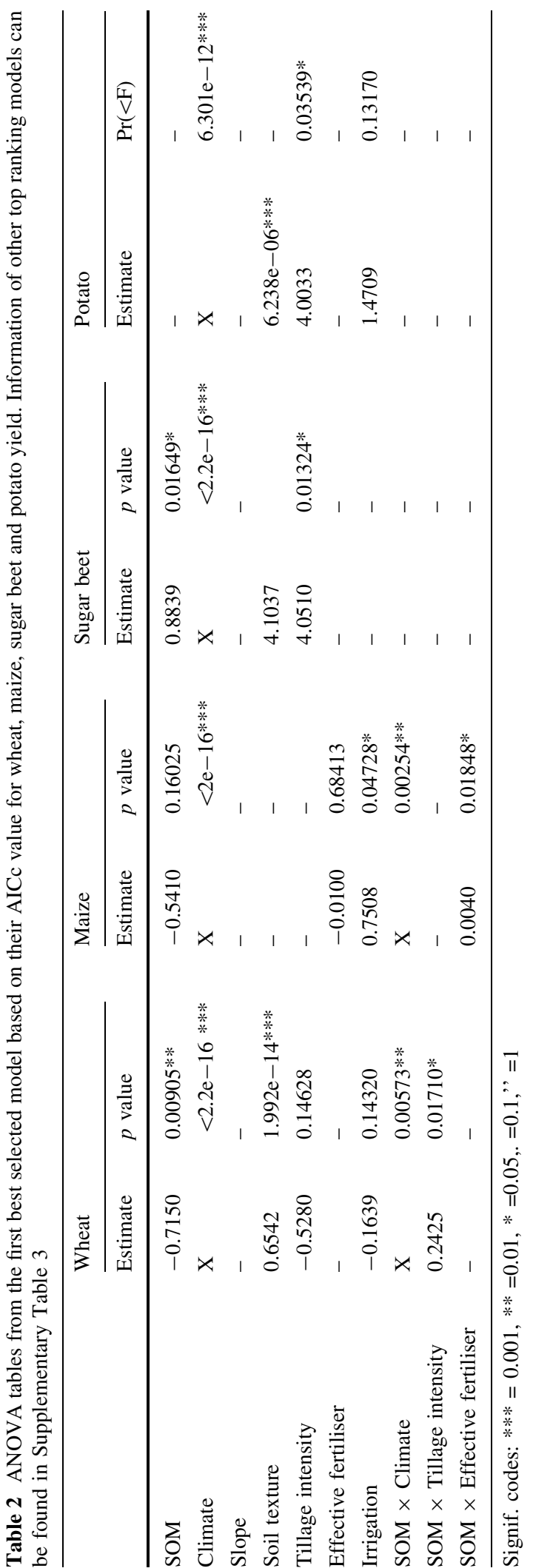

half of the top ranking models. However, only for wheat and sugar beet the effect size of SOM on crop yield was significant. For these two crops, the effect sizes within the top ranking models with a similar AICc value is provided in Supplementary Tables 4 and 5.

Correcting for the influence of other co-variables, across the different multiple regression models, wheat yields were on average $263 \pm 4$ (95\% confidence interval-CI) $\mathrm{kg} \mathrm{ha}^{-1}$ higher on soils with one percentage point more SOM in the Continental climate. In the Atlantic climate, wheat yields were on average $75 \pm 2(95 \% \mathrm{CI}) \mathrm{kg} \mathrm{ha}^{-1}$ lower on soils with one percentage point more SOM $(p<0.046)$. Sugar beet yield was positively correlated with SOM in all climate zones $(p=0.016)$, with on average $1007 \pm 157$ (95\% CI) kg yield increase per percentage point SOM. However, this value depended on a small number of low yield observations. Excluding these points $(\mathrm{N}=9)$ resulted in more similar top ranking models. SOM was included in 11 of the 20 top ranking models only, with yields being on average $75 \pm 279$ (95\% CI) kg higher per percentage point SOM in all climate zones. For potato and maize, there was no significant effect of SOM on crop yields when correcting for the influence of other co-variables.

The models with highest AICc value (Table 2; Supplementary Table 3) were selected to further analyse the role of SOM, as they are similar $(\triangle \mathrm{AICc}<2)$ to the other best models. For wheat, interactions between SOM and climate, and SOM and tillage intensity were included in the selected best model. For maize, interactions between SOM and climate, and SOM and effective fertiliser were included (Table 2). For all crop types, crop yields differed significantly between climate zones.

Another notable result is the effect of soil texture and tillage on sugar beet yield, i.e. a finer soil texture and more intensive tillage was correlated with higher sugar beet yield (Table 2). The effect of soil texture did not depend on the low yield observations, but tillage $\operatorname{did}(p=0.076$ without low yield observations). For potato, more intensive tillage was also correlated with higher yields.

Effect of SOM on minimum and attainable yields

For wheat, the lower quantile of yields had a significant positive slope $(p<0.001$, dotted line in 
Fig. 1). This shows that for wheat, higher SOM is correlated with a higher minimum yield. There was no significant effect on attainable or minimum yield for the other crops investigated. The lower quantile of the sugar beet data had a close to significant positive slope $(p=0.067)$.

\section{Discussion}

Correlations between SOM and yields differ per crop type and climate zone

Our results show that, when present, correlations between reported SOM and crop yields differ per crop type and climate zone. In other cases, such correlations were absent. The negative correlation between SOM content and observed wheat yields in the Atlantic climate correspond well to recent findings for Denmark of Schjønning et al. (2018) and Oelofse et al. (2015) who found a negative effect of SOM content on potentials yields in the same climate. The positive correlations found between SOM and sugar beet yields in all climate zones correspond well to other studies, such as those by Oldfield et al. (2019), Hijbeek et al. (2017a), and Verheijen (2005), who suggested that there is more evidence of a positive effect of SOM on yields of root and tuber crops than on cereal yields. This was partly supported by this study but needs more investigation as the finding relied on a small number of data points and potato yield was not correlated with SOM content.

There was no consistent correlation between the other co-variables (such as soil texture, tillage intensity or irrigation) and crop yield, except for the influence of climate as discussed above. For example, sugar beet and wheat yields were found to be higher with finer soils, perhaps related to an improved water or nutrient holding capacity of these soils. However, it is surprising that a similar correlation was not found for potato and maize. SOM content was found to differ across climate zones, with highest SOM values being reported in the Atlantic climate, followed by the Continental and Mediterranean climate. This corresponds well with observations that increasing SOM is more difficult in a warmer climate (Leirós et al. 1999; Miller et al. 2004). At the same time, less variation in the reported SOM contents in the Mediterranean climate might also explain why it was more challenging to find correlations with crop yields. In addition, as thresholds for SOM content are currently uncertain (Hijbeek et al. 2017b), it is unknown if the ranges of SOM content in the different climate zones were sufficient to observe yield effects.

Similarity in findings between field experiments and farmers' observations

Whilst many studies have investigated the relation between SOM content and crop yields using experimental data (e.g. Dawe et al. 2003; Han et al. 2018; Oelofse et al. 2015; Pan et al. 2009), we were not aware of published studies which rely on farmers' perceptions. The similarities between our results and previous studies are therefore the more striking as these previous studies were based on experimental conditions, while this study was based on farmers observations, often in more heterogeneous conditions.

Using minimum yield as an indicator the effect of SOM on crop yields

In our study, the upper quantile of crop yields was assumed to be representative for attainable yields (highest farmers' yields) at a given SOM content, while the lower quantile was assumed to be representative for minimum crop yields at a certain SOM content. Unlike previous studies who also used the concept of attainable yield (i.e. Hijbeek et al. 2017a; Oelofse et al. 2015; Schjønning et al. 2018), in our study no significant effect of SOM on attainable yield was found. This deviation might be caused by the difference in measurement of attainable yield: previous studies based estimates of attainable yield on nitrogen response curves in controlled experimental settings, while we relied on the upper quantile of the yield cloud of farmers' observations, inherently containing more variation. Our study did, however, find that a higher SOM content was significantly positively correlated with higher minimum wheat and slightly positively correlated with minimum sugar beet yields. This study therefore suggests that besides attainable yield, minimum yield might also be a useful indicator to assess yield effects of SOM. 
Limitations of this study

\section{Confounding factors}

Finding effects of SOM on crop yield across different climates and soil types is inherently problematic as soil types and climates not only influence the SOM content but also have a direct impact on crop yields and crop management, giving rise to potential confounding factors (Hijbeek et al. 2018). In our study, where possible, we have assessed the effect of SOM on crop yields within climate zones. In addition, we have included soil texture as an explanatory variable in our model and thereby assessed the added value of including SOM, next to soil texture, in explaining variation in observed crop yields.

\section{Using farm survey data}

With this study, we did not aim to give a definitive answer to the question what the role of SOM is for crop yields. Rather, we hope that by sharing farmers' observations (a relatively underexploited data source on this topic) and comparing these with findings from agronomic field experiments, we have added one more building block to the puzzle. Benefits of farm survey data include gaining insight in actual on-farm situations and perceptions, and an improved ability to explain effects to farmers. The use of farm survey data, however, also has several limitations, of which we will discuss the main ones below.

In this study, we relied on reported values for average SOM content and representative crop yields at farm level by farmers. First, this will have caused more variation in the data than if one researcher would have made all the measurements using a more standardized approach. For example, the reported values on SOM might have been based on different sampling depths. The effect of this on reported values is unknown and could therefore not be included in the analysis. On the other hand, our approach probably positively affected the sample size of the dataset. To diminish the impact, farmers were given the option to report if they were aware or not of their average SOM content, which will have led to more precise answers, but might also have led to a bias in the data set towards farmers who measure their SOM content more often. Moreover, as representative crop yields of recent years were requested, yield extremes might not always have been included. It is not known to which extent this affects the correlation between SOM and crop yield.

A second limitation of the approach is that average SOM, crop yield and management (such as fertiliser use, tillage and irrigation) information was requested for the entire farm, rather than for individual fields. In reality, farmers most likely differentiate crop management across fields and crops, and SOM and crop yields may differ between fields within a farm. If field and crop-level data would have been available, possibly more of the variation in yield could have been explained by management factors (e.g. Silva et al. 2017), and better correlations might have been found between SOM and crop yield. Also, we cannot exclude that other attributes such as tillage depth and date of application would affect the data. To account for this variation in the farm survey data, quantile regressions were performed. The conducted quantile regression could have been improved when conducted per climate zone or soil texture, however sample sizes were too small to allow for this.

Finally, the farm survey could not account for differences in soil life or fractions of SOM, whilst this could be of importance when determining the relationship between SOM and crop yield (Six and Jastrow 2002).

\section{Model selection}

The effect of SOM on crop yields was analysed based on a model selection. In literature, much uncertainty exists about model selection strategies. Thoughtless model selection is repeatedly mentioned as leading to model overfitting, which results in finding effects that are false in reality (Burnham and Anderson 2002). To avoid this, we considered both the first selected model and lower ranked models with a similar AICc value. Additionally, we used a full model, which includes all parameters, to compare with the selected models.

\section{Conclusions and recommendations}

SOM is often mentioned as a soil quality indicator, but this study, based on farmers' perceptions, only partly supports the claim that SOM has a positive effect on crop yield. Based on the presented results, increasing SOM seems to be most relevant in Europe when cultivating root or tuber crops (such as sugar beet) or 
wheat in a Continental climate. This study does not intend to suggest that SOM should be ignored as a soil quality indicator or does not provide other important ecosystem services in current European farm practices, but our findings do provide little evidence for a consistent causal relation between SOM and crop yields across climates and crop types.

Our study was based on farmers' reporting of the SOM content of their soils. If research funds would allow for more operational costs and logistics, future research could improve our analysis by including soil samples and in-field measurements of an array of soil properties, potentially improving insights into underlying mechanisms. The study also relied on farmers' reports on crop yields being representative for the last few years. If possible, future research could investigate the role of SOM on annual variation in crop yields, especially focussing on more extreme weather events (such as very dry or wet years), potentially enhancing insights into the function of SOM for soil resilience.

To increase SOM content in agricultural soils, farmers' support is essential. Our findings suggest that only in specific conditions an effect of SOM on crop yield is observed, either positive or negative. In the positive cases, support from farmers to increase SOM can be gained by highlighting these benefits. In other cases, support has to be gained through other incentives. Our findings therefore indicate the need for a diversified strategy across soil types, crops and climates when seeking farmers' support to increase SOM.

Acknowledgements Our gratitude goes to all European farmers who spared some of their time to fill in the questionnaire. Setting up a large scale-farm survey would not have been possible without numerous colleagues across different institutes. First, we thank Hein ten Berge (WUR) for coordinating the $\mathrm{Catch}-\mathrm{C}$ project. In Austria, main contacts were the provincial and regional officials of the chamber of agriculture in Lower Austria. We thank Norman Schlatter and Taru Sanden (AGES) for helping out with the survey. In Belgium, data was collected with the help of Erwin Wauters and Jo Bijttebier (ILVO). In Italy, we received support from universities of Ancona, Bari, Milano, Napoli Udine, Pisa, Teramo, Tuscia, Ancona and Perugia; provincial and regional officials; farmers unions (Coldiretti, Confagricoltura, Confederazione Italiana Agricoltori); CadirLab (Quargnento, AL); Consorzio Agrario di Siena; advisors of the Italian Farm Accountancy Data Network; Chiara Costamagna; students of the University of Torino and University of Milano. In the Netherlands, Rob Smidt (WUR) helped with extracting farmers' addresses from the database and Bert Rijk (WUR) supported the survey logistics. In Germany, data was collected with the help of Janine Mallast (IGZ), Isabell Raschke and Magdalena Werner (University of Göttingen). We thank all colleagues for their efforts and support.

Authors' contributions Set up of the research: W.J.V., R.H., M.K.I., P.R. Data collection: R.H., L.Z., L.B., G.G., A.P., H.S., H.H.S., G.R. Data analysis: W.J.V., R.H., M.I., P.R. Writing of the manuscript: W.J.V., R.H., M.I., P.R., L.Z., L.B., G.G., A.P., H.S., H.H.S., G.R

Funding Data collection for this publication was financially supported by the European Commission under the CATCH-C project (Grant Agreement $\mathrm{N}^{\circ}$ 289782) within the 7th Framework Programme for Research, Technological Development and Demonstration. Its content does not represent the official position of the EC and is entirely the responsibility of the authors.

\section{Compliance with ethical standards}

Conflicts of interest The authors declare that they have no conflict of interest.

Availability of data and material Data will be published on a data portal upon acceptance.

Open Access This article is licensed under a Creative Commons Attribution 4.0 International License, which permits use, sharing, adaptation, distribution and reproduction in any medium or format, as long as you give appropriate credit to the original author(s) and the source, provide a link to the Creative Commons licence, and indicate if changes were made. The images or other third party material in this article are included in the article's Creative Commons licence, unless indicated otherwise in a credit line to the material. If material is not included in the article's Creative Commons licence and your intended use is not permitted by statutory regulation or exceeds the permitted use, you will need to obtain permission directly from the copyright holder. To view a copy of this licence, visit http://creativecommons.org/licenses/by/4.0/.

\section{References}

Asirifi K, Morgan WC, Parbery D (1994) Suppression of Sclerotinia soft rot of lettuce with organic soil amendments. Aust J Exp Agric 34:131-136

Barton K (2019) MuMIn: multi-model inference v.1.43.6. https://CRAN.Rproject.org/package=MuMIn.

Bijttebier J et al (2015) Farmers review of best management practices: drivers and barriers as seen by adopters and nonadopters. Catch-C project: Report D4:422

Burnham KP, Anderson DR (2002) Model selection and multimodel inference: a practical information-theoretic approach, 2nd edn. Springer, New York

Chen J-H (2006) The combined use of chemical and organic fertilizers and/or biofertilizer for crop growth and soil 
fertility. In: International workshop on sustained management of the soil-rhizosphere system for efficient crop production and fertilizer use. Citeseer, Princeton, p 20

Darby HM, Stone AG, Dick RP (2006) Compost and manure mediated impacts on soilborne pathogens and soil quality. Soil Sci Soc Am J 70:347-358

Dawe D et al (2003) Do organic amendments improve yield trends and profitability in intensive rice systems? Field Crop Res 83:191-213

de Moraes Sa JC, Tivet F, Lal R, Briedis C, Hartman DC, dos Santos JZ, dos Santos JB (2014) Long-term tillage systems impacts on soil $\mathrm{C}$ dynamics, soil resilience and agronomic productivity of a Brazilian Oxisol. Soil Tillage Res 136:38-50

EUFADN (2019) ec.europa.eu. Accessed 19 Dec 2019

Fox J (2018) Car: companion to applied regression. The Comprehensive R Archive Network

Giraud C (2014) Introduction to high-dimensional statistics, vol 138. Chapman and Hall/CRC, London

Han X, Xu C, Dungait JA, Bol R, Wang X, Wu W, Meng F (2018) Straw incorporation increases crop yield and soil organic carbon sequestration but varies under different natural conditions and farming practices in China: a system analysis. Biogeosciences 15:1933-1946

Hijbeek R, Cormont A, Hazeu G, Bechini L, Zavattaro L, Janssen B et al (2017) Do farmers perceive a deficiency of soil organic matter? A European and farm level analysis. Ecol Ind 83:390-403

Hijbeek R, van Ittersum MK, ten Berge HF, Gort G, Spiegel H, Whitmore AP (2017) Do organic inputs matter-a metaanalysis of additional yield effects for arable crops in Europe. Plant Soil 411:293-303

Hijbeek R, van Ittersum MK, ten Berge HF, Whitmore AP (2018) Evidence review indicates a re-think on the impact of organic inputs and soil organic matter on crop yield. In: 2018 IFS Agronomic Conference, Cambridge, UK, 2018. International Fertiliser Society.

Koenker R, Portnoy S, Tian Ng P (2019) quantreg: quantile regression. https://CRAN.Rproject.org/package=MuMIn.

Leirós MC, Trasar-Cepeda C, Seoane S, Gil-Sotres F (1999) Dependence of mineralization of soil organic matter on temperature and moisture. Soil Biol Biochem 31:327-335

Loveland P, Webb J (2003) Is there a critical level of organic matter in the agricultural soils of temperate regions: a review. Soil Tillage Res 70:1-18

Lucas S, Weil R (2012) Can a labile carbon test be used to predict crop responses to improve soil organic matter management? Agron J 104:1160-1170
Metzger MJ, Bunce RGH, Jongman RH, Mücher CA, Watkins JW (2005) A climatic stratification of the environment of Europe. Glob Ecol Biogeogr 14:549-563

Miller AJ, Amundson R, Burke IC, Yonker C (2004) The effect of climate and cultivation on soil organic $\mathrm{C}$ and N. Biogeochemistry 67:57-72

Nyamangara J, Gotosa J, Mpofu S (2001) Cattle manure effects on structural stability and water retention capacity of a granitic sandy soil in Zimbabwe. Soil Tillage Res 62:157-162

Oelofse M, Markussen B, Knudsen L, Schelde K, Olesen JE, Jensen LS, Bruun S (2015) Do soil organic carbon levels affect potential yields and nitrogen use efficiency? An analysis of winter wheat and spring barley field trials. Eur J Agron 66:62-73

Oldfield EE, Bradford MA, Wood SA (2019) Global metaanalysis of the relationship between soil organic matter and crop yields. Soil 5:15-32

Oldfield EE, Wood SA, Bradford MA (2020) Direct evidence using a controlled greenhouse study for threshold effects of soil organic matter on crop growth. Ecol Appl 30:e02073

Pan G, Smith P, Pan W (2009) The role of soil organic matter in maintaining the productivity and yield stability of cereals in China. Agric Ecosyst Environ 129:344-348

Pribyl DW (2010) A critical review of the conventional SOC to SOM conversion factor. Geoderma 156:75-83

Russell E (1977) The role of organic matter in soil fertility. Philos Trans R Soc Lond B Biol Sci 281:209-219

Schjønning P et al. (2018) The role of soil organic matter for maintaining crop yields: evidence for a renewed conceptual basis. In: Advances in agronomy, vol 150. Elsevier, New York, pp 35-79

Silva JV, Reidsma P, van Ittersum MK (2017) Crop yields gaps in Dutch arable farming systems: analysis at crop and crop rotation level. Agric Syst 158:78-92

Six J, Jastrow JD (2002) Organic matter turnover. In: Encyclopedia of soil science, pp 936-942

van Noordwijk M, Cerri C, Woomer PL, Nugroho K, Bernoux M (1997) Soil carbon dynamics in the humid tropical forest zone. Geoderma 79:187-225

Verheijen FG (2005) On-farm benefits from soil organic matter in England and Wales. Cranfield University

Zebarth B, Neilsen G, Hogue E, Neilsen D (1999) Influence of organic waste amendments on selected soil physical and chemical properties. Can J Soil Sci 79:501-504

Publisher's Note Springer Nature remains neutral with regard to jurisdictional claims in published maps and institutional affiliations. 